\title{
Karapınar Deresi (Erdemli, Mersin) Üzerinde Bulunan Alabalık Tesislerinin Su Kalitesine Etkileri
}

\author{
Hacer Merve KOCA ${ }^{1 *}$, Mehmet Tahir ALP'D \\ ${ }^{1}$ Ankara Üniversitesi, Ziraat Fakültesi, Su Ürünleri Mühendisliği Bölümü, Ankara, Türkiye \\ ${ }^{2}$ Mersin Üniversitesi, Su Ürünleri Fakültesi, İç Sular Biyolojisi Anabilim Dalı, Mersin, Türkiye
}

*Sorumlu Yazar: hmervekoca@gmail.com

Araștırma Makalesi

Geliş 09 Mayıs 2020; Kabul 22 Haziran 2020; Basım 01 Aralık 2020.

Alıntılama: Koca, H. M., \& Alp, M. T. (2020). Karapınar deresi (Erdemli, Mersin) üzerinde bulunan alabalık tesislerinin su kalitesine etkileri. Acta Aquatica Turcica, 16(4), 516-524. https://doi.org/10.22392/actaquatr.734665

\section{Özet}

Bu çalışma, Karapınar Deresi üzerinde bulunan 3 alabalık tesisinin su kalite parametreleri üzerindeki etkilerini incelemek amacıyla Ocak - Aralık 2012 tarihleri arasında gerçekleştirilmiştir.

Çalışmada incelenen su kalite parametrelerinden sicaklık $15,6-17,9{ }^{\circ} \mathrm{C}, \mathrm{pH} 7$ - 7,94, çözünmüş oksijen $6,04-9,75 \mathrm{mg} / 1$, elektriksel iletkenlik 431,0 - 545,0 $\mu \mathrm{s} / \mathrm{cm}$, askıda katı madde $0,1-18,2 \mathrm{mg} / \mathrm{l}$, klorofil- $a$ 0,12 - 11,38 mg/m $\mathrm{m}^{3}$, toplam alkalinite 280 - $510 \mathrm{CaCO} / \mathrm{l}$, toplam sertlik 285 - 397,1 CaCO3/l, kimyasal oksijen ihtiyac1 $27-79 \mathrm{mg} / \mathrm{l}$, nitrit azotu 0,001 - 0,015 $\mathrm{mg} / \mathrm{l}$, nitrat azotu $0,54-0,87 \mathrm{mg} / \mathrm{l}$, amonyum azotu $0,018-0,033 \mathrm{mg} / \mathrm{l}$, ortofosfat $0,002-0,009 \mathrm{mg} / \mathrm{l}$, toplam azot $0,68-1,07$ $\mathrm{mg} / \mathrm{l}$, toplam fosfor $0,016-0,030 \mathrm{mg} / \mathrm{l}$, sedimentte toplam kjeldahl azotu 841 - $1436 \mathrm{mg} / \mathrm{kg}$ ve sedimentte toplam fosfor 95 $145 \mathrm{mg} / \mathrm{kg}$ aralığında değişmiştir.

Sonuç olarak, Karapınar Deresinde su kalitesi, su kirliliği kontrol yönetmeliğine (SKKY) göre sıcaklık, pH, çözünmüş oksijen, kimyasal oksijen ihtiyacı, nitrit azotu, nitrat azotu, amonyum azotu ve toplam fosfor değerleri yönünden I. sınıf olarak belirlenmiştir. Bu durumun alabalık çiftliklerinin kapasitelerinin düşük ve yemleme yoğunluğunun az olmasından kaynaklandığı düşünülmektedir. Tüketilmeyen yem ve balıkların metabolik faaliyetlerinden kaynaklanan atıkların, yüksek debi sayesinde birikim yapmadığı tespit edilmiştir.

Anahtar Kelimeler: Su kirliliği, su kalitesi, alabalık çiftliği, Karapınar Deresi

The Effect of Trout Fish Farms on Water Quality of Karapınar Creek ( Erdemli, Mersin)

\begin{abstract}
This study was carried out to determine the effect of three trout fish farms on the water quality of Karapınar Creek between January - December 2012.

During the study, measured water quality parameters varied in different ranges, water temperature $15.6-17.9{ }^{\circ} \mathrm{C}, \mathrm{pH} 7$ 7.94, dissolved oxygen $6.04-9.75 \mathrm{mg} / \mathrm{l}$, electrical conductivity $431.00-545.00 \mu \mathrm{s} / \mathrm{cm}$, suspended solid matter $0.1-18.2$ $\mathrm{mg} / \mathrm{l}$, chlorophyll-a $0.12-11.38 \mathrm{mg} / \mathrm{m}^{3}$, total alkalinity $280-510 \mathrm{CaCO}_{3} / 1$, total hardness $285-397.1 \mathrm{CaCO}_{3} / 1$, chemical oxygen demand $27-79 \mathrm{mg} / \mathrm{l}$, nitrite nitrogen $0.001-0.015 \mathrm{mg} / \mathrm{l}$, nitrate nitrogen $0.54-0.87 \mathrm{mg} / \mathrm{l}$, ammonium nitrogen 0.018 - $0.033 \mathrm{mg} / \mathrm{l}$, orthophosphate $0.002-0.009 \mathrm{mg} / \mathrm{l}$, total nitrogen $0.68-1.07 \mathrm{mg} / \mathrm{l}$, total phosphorus $0.016-0.030 \mathrm{mg} / \mathrm{l}$, sediment total kjeldahl nitrogen $841-1436 \mathrm{mg} / \mathrm{kg}$ and sediment total phosphorus $95-145 \mathrm{mg} / \mathrm{kg}$.

In conclusion, according to the Water Pollution Control Regulation of Inland Water Resources Criteriathe creek can bewas classified as I. class (high quality water) with regard to water temperature, dissolved oxygen, chemical oxygen demand, nitrite-nitrogen, nitrate-nitrogen, ammonium-nitrogen and total phosphorus. This situation might be related tothe low capacity of trout farms and low feeding intensity. It was also determined that non-consumed feed and wastes from metabolic activities of fish did not accumulate due to the high flow rate.
\end{abstract}

Keywords: Water pollution, water quality, trout farm, Karapınar Creek

\section{GİRIŞ}

Su ürünleri yetiştiriciliği gün geçtikçe büyümeye devam eden bir sektördür. Yetiştiricilik üretimi son 30 yıl içerisinde dünya genelinde yıllık ortalama \%8,8 artış ile neredeyse 12 kat artmıştır (FAO, 2018). Ülkemizde 314,537 ton olan su ürünleri yetiştiriciliğinin \%33,4'ü iç sularda gerçekleştirilmiştir (Anonim, 2019). Son yıllarda artan yetiştiricilik faaliyetleriyle birlikte yetiştiricilikten kaynaklı atık suların akarsulara karışması sonucu, akarsuların su kalitesinin bozulması da gündeme gelmiştir. Birçok araştırmacı iç sularda balık yetiştiriciliğinden kaynaklanan kirliliğin akarsular üzerindeki 
etkilerini araştırmış (Pulatsü vd., 2004; Tanigawa vd., 2007; Manoochehri vd., 2010; Fadaeifard vd., 2012; Saremi vd., 2013) ve su ürünleri yetiştiriciliğinin, çevre ve doğal kaynaklar üzerine etkilerini dile getirmişlerdir.

Su ürünleri yetiştiricilik sistemlerinin çıkış suları, alıcı sularda besin elementi yoğunluğunu artıran, oksijeni azaltan, ötrofikasyon ve bulanıklığ doğrudan etkileyen atıklar içermektedir. Bu çıkış suları, ötrofikasyona yol açan özellikle fosfat ve nitrat gibi besin elementleri ile organik madde miktarının fazla olması nedeniyle biyolojik oksijen ihtiyacı $\left(\mathrm{BOI}_{5}\right)$ ve kimyasal oksijen ihtiyacını (KOI) artırarak, oksijen dengesi üzerinde istenmeyen etkiye sahip maddeleri içermesi nedeniyle önem taşımaktadır. Bu sular arıtılmadan deşarj edildiğinde, alıcı suyun kalitesi üzerinde ciddi bir olumsuz etkiye sebep olabilir (Saremi vd., 2013). Balık çiftliklerinin atık sularının fizikokimyasal parametrelerinin ve çevreye olan etkilerinin belirlenmesi, atık su sistemlerinin yönetilmesine yardımcı olacaktır (Pulatsü vd., 2004).

Teknolojinin gelişmesiyle birlikte sucul yetiştiricilik sistemlerinin daha fazla su, yem ve kimyasal madde deşarjının sucul ekosisteme zarar verdiği düşüncesiyle, bu konu üzerinde çalışmalar başlamıştır. Bu amaçla, EPA (Environmental Protection Agency) tarafından uluslararası atık su kalite kriterleri belirlenmiştir (EPA, 1986; Millen ve Redding, 1998). Aynı zamanda Avrupa Birliği ülkeleri tarafından 2000 yılında kabul edilen Su Çerçeve Direktifi (SÇD); yeraltı suları, yüzey suları, kıyılar ve denizlerde meydana gelen kirlilik etmenlerinin, kaynaklarında engellenerek tüm bu kirlilik kaynaklarının sürdürülebilir kontrolü için bir mekanizma oluşturulmasını gerektirmektedir (Akkaya vd., 2006).

Çalışmanın yapıldığı Karapınar Deresi etrafında tarım arazileri, büyükbaş hayvan çiftlikleri ve yerleşim alanları bulunmakta, dere suyu alabalık çiftliklerinin yanı sıra bölgenin içme ve kullanma suyunu karşılaması ve tarım arazileri için sulama suyu olarak kullanılmaktadır. Bu sebeplerle balık işletmelerinin çıkış sularının özelliklerinin belirlenmesi ve su ürünleri yetiştiriciliğinin çevre üzerindeki etkisinin tespiti önem teşkil etmektedir. Bu çalışmada Karapınar Deresi üzerinde bulunan ardışık 3 alabalık çiftliğinin çıkış sularının su kalitesine etkilerinin belirlenmesi amaçlanmıştır.

\section{MATERYAL ve YÖNTEM}

Proje çalışması, Mersin İli’ne 25 km uzaklıktaki Erdemli İlçesi, Kargıpınarı beldesi mevkiinde bir dağ kaynağı olan Karapınar Deresi üzerinde gerçekleştirilmiştir. Karapınar Deresi üzerinde ardışık 3 alabalık işletmesi bulunmakta, her işletmenin çıkış suyu kendinden bir sonraki işletmenin besleme suyuna karışmaktadır. İşletmeler sırasıyla 8,15 ve 10 ton/y1l üretim kapasitesine sahiptir. İstasyon 1 Karapınar Deresi'nin başlangıç kısmı olup ilk işletmenin giriş bölgesi, istasyon 2 ilk işletmenin çıkış noktası, istasyon 3 ikinci işletmenin giriş noktası, istasyon 4 ikinci işletmenin çıkış noktası ve istasyon 5 üçüncü işletmenin çıkış noktasından Karapınar Deresi üzerinden seçilmiştir.

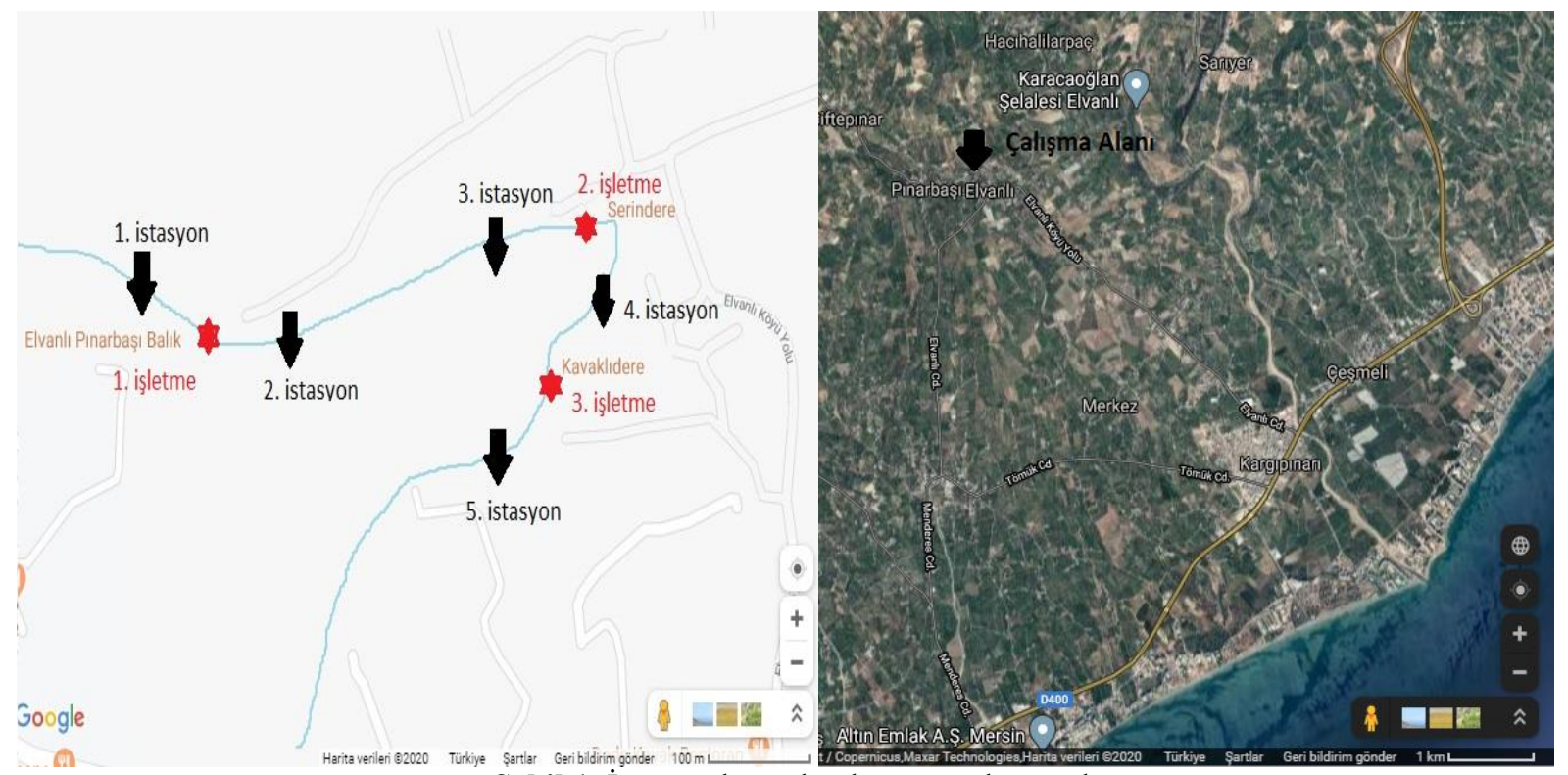

Şekil 1. İstasyonların dağılımı ve çalışma alanı 
Örneklemeler, Ocak-Aralı 2012 tarihleri arasinda 5 istasyonda aylik periyotlarla gerçekleştirilmiştir. Çözünmüş oksijen (ÇO), pH, sıcaklık (T) ve elektriksel iletkenlik (Eİ) değerleri HachLange marka HQ40D model Multi ölçüm cihazı ile arazide yerinde ölçülmüştür. Kimyasal ve diğer fiziksel parametrelerin ise standart metotlara göre analizleri yapılmıştır (APHA, 1998). Laboratuvara getirilen su örneklerinin süzme düzeneklerinde $0,45 \mu \mathrm{m}$ gözenek açıklığına sahip Whatman marka GF/C cam mikrofiber filtrelerden süzülmesinin hemen ardından toplam sertlik (TS), toplam alkalinite (TA), nitrit azotu $\left(\mathrm{NO}_{2}-\mathrm{N}\right)$, nitrat azotu $\left(\mathrm{NO}_{3}-\mathrm{N}\right)$, amonyum azotu $\left(\mathrm{NH}_{4}-\mathrm{N}\right)$, ortofosfat $\left(\mathrm{PO}_{4}-\mathrm{P}\right)$ ve klorofil- $a(\mathrm{Kl}-a)$ analizleri yapılmıştır. Toplam azot (TN), toplam fosfor (TP) ve kimyasal oksijen ihtiyacı (KOİ) analizleri için kullanılacak süzülmemiş su örnekleri 24 saat içinde analiz edilmiştir (APHA, 1998). Akış hızının düşük olduğu bölgeden sedimentin en üst katmanından alınan sediment örnekleri, koyu renkli polietilen torbalarla laboratuvara ulaştırılmışıtır. Sedimentte Toplam Kjeldahl Azotu (SD-TN) kjeldahl metoduna göre, Sedimentte Toplam Fosfor (SD-TP) ise spektrofotometrik olarak belirlenmiştir (APHA, 1998). 3. istasyon mevkiinde dip yapısının kayalık olması nedeniyle sediment örneği alınmamıştır.

Tüm analizler için SPSS 19.9 programı kullanılmıştır. Örnekleme noktalarında su kalitesi değişkenleri arasındaki ilişkileri belirlemek amacıyla Spearman korelasyon analizi yapılmıştır. Su kalite parametrelerinin istasyonlara göre farklılıkları Varyans Analizi ve Tukey testi ile değerlendirilmiştir. Tüm parametreler bakımından düşük ve yüksek akımlar arasındaki farklılıklar $\mathrm{p}<0,05$ 'e göre anlamlı kabul edilmiştir. Elde edilen sonuçlar çiftliklerin akarsu su kalitesine etkilerini belirlemek amaciyla Su Kirliliği Kontrol Yönetmeliğine göre değerlendirilmiştir (SKKY, 2004).

\section{BULGULAR}

Karapınar deresi üzerindeki alabalık çiftliklerinin su kalite parametrelerine ilişkin veriler Tablo 1'de, izlenen değişkenler arasındaki istatistiksel olarak önemli ilişkiler Tablo 2'de, sedimentte toplam azot ve toplam fosfor değerlerinin ortalama değerleri Tablo 3 'de verilmiş̧ir.

Tablo 1. Karapınar deresi üzerindeki alabalık çiftliklerinin su kalite parametrelerinin istasyonlara göre değişimi (ortalama \pm Standart hata)

\begin{tabular}{|c|c|c|c|c|c|}
\hline Parametre & 1.istasyon & 2.istasyon & 3.istasyon & 4.istasyon & 5.istasyon \\
\hline $\mathrm{T}\left({ }^{0} \mathrm{C}\right)$ & $16,6 \pm 0,4$ & $16,4 \pm 0,4$ & $16,6 \pm 0,4$ & $16,6 \pm 0,5$ & $16,7 \pm 0,6$ \\
\hline $\mathrm{PH}$ & $7,4 \pm 0,1^{\mathrm{a}}$ & $7,6 \pm 0,{ }^{1 b}$ & $7,7 \pm 0,1^{\mathrm{b}}$ & $7,6 \pm 0,1^{b}$ & $7,7 \pm 0,2^{b}$ \\
\hline ÇO (mg/l) & $7,5 \pm 0,6^{\mathrm{a}}$ & $8,7 \pm 0,2^{b}$ & $8,9 \pm 0,2^{b}$ & $9,0 \pm 0,3^{b}$ & $9,0 \pm 0,4^{b}$ \\
\hline $\mathrm{EI}(\mu \mathrm{s} / \mathrm{cm})$ & $522 \pm 15$ & $521 \pm 17$ & $518 \pm 18$ & $520 \pm 17$ & $520 \pm 17$ \\
\hline AKM (mg/l) & $4,3 \pm 3,6$ & $5,6 \pm 4,0$ & $6,6 \pm 5,8$ & $5,4 \pm 5,6$ & $5,7 \pm 4,2$ \\
\hline $\mathrm{Kl}-a(\mu \mathrm{g} / \mathrm{l})$ & $0,93 \pm 0,43^{\mathrm{a}}$ & $0,77 \pm 0,58^{\mathrm{a}}$ & $0,41 \pm 0,25^{\mathrm{ab}}$ & $0,31 \pm 0,23^{\mathrm{b}}$ & $0,48 \pm 0,42^{\mathrm{ab}}$ \\
\hline $\mathrm{TA}\left(\mathrm{mg} \mathrm{CaCO} \mathrm{Ca}_{3} / \mathrm{l}\right)$ & $375 \pm 36$ & $361 \pm 38$ & $376 \pm 36$ & $376 \pm 45$ & $374 \pm 45$ \\
\hline $\mathrm{TS}\left(\mathrm{mg} \mathrm{CaCO}_{3} / \mathrm{l}\right)$ & $341 \pm 26$ & $349 \pm 32$ & $359 \pm 24$ & $354 \pm 13$ & $356 \pm 11$ \\
\hline KOİ (mg/l) & $53 \pm 8,5$ & $42 \pm 13,5$ & $55 \pm 19$ & $54 \pm 9,9$ & $48 \pm 6,2$ \\
\hline $\mathrm{NO}_{2}(\mathrm{mg} / \mathrm{l})$ & $0,006 \pm 0,004$ & $0,005 \pm 0,004$ & $0,005 \pm 0,004$ & $0,006 \pm 0,004$ & $0,006 \pm 0,004$ \\
\hline $\mathrm{NO}_{3}(\mathrm{mg} / \mathrm{l})$ & $0,69 \pm 0,10$ & $0,71 \pm 0,09$ & $0,72 \pm 0,08$ & $0,71 \pm 0,08$ & $0,71 \pm 0,07$ \\
\hline $\mathrm{NH}_{4}(\mathrm{mg} / \mathrm{l})$ & $0,024 \pm 0,005$ & $0,023 \pm 0,005$ & $0,024 \pm 0,00$ & $0,025 \pm 0,005$ & $0,024 \pm 0,004$ \\
\hline $\mathrm{PO}_{4}(\mathrm{mg} / \mathrm{l})$ & $0,004 \pm 0,001$ & $0,004 \pm 0,001$ & $0,004 \pm 0,001$ & $0,004 \pm 0,002$ & $0,004 \pm 0,001$ \\
\hline $\mathrm{TN}(\mathrm{mg} / \mathrm{l})$ & $0,92 \pm 0,07$ & $0,89 \pm 0,08$ & $0,87 \pm 0,06$ & $0,91 \pm 0,05$ & $0,88 \pm 0,05$ \\
\hline $\mathrm{TP}(\mathrm{mg} / \mathrm{l})$ & $0,020 \pm 0,005$ & $0,019 \pm 0,004$ & $0,019 \pm 0,004$ & $0,019 \pm 0,004$ & $0,019 \pm 0,004$ \\
\hline
\end{tabular}

Aynı satırda farklı üstel harflerle gösterilen değerler istatistiksel olarak önemli farklılığı temsil eder; P $<0,01$; Tukey's HSD 
Tablo 2. İzlenen değişkenler arasındaki istatistiksel olarak önemli ilişkiler $(\mathrm{P}<0,05$; Spearman korelasyonu $)$

\begin{tabular}{|c|c|c|c|c|c|c|c|c|c|c|c|c|c|}
\hline & ÇO & EI & AKM & TS & TA & $\mathrm{NO}_{2}$ & $\mathrm{NH}_{4}$ & $\mathrm{NO}_{3}$ & $\mathrm{TN}$ & $\mathrm{PO}_{4}$ & TP & $\mathrm{Kl}-a$ & KOİ \\
\hline $\mathbf{T}$ & & 0,29 & 0,29 & & & & & 0,29 & & 0,36 & & & 0,32 \\
\hline pH & 0,47 & 0,27 & 0,47 & 0,34 & 0,31 & & & 0,35 & & & & $-0,37$ & \\
\hline ÇO & & $-0,42$ & & & & & & & & & & $-0,44$ & \\
\hline EI & & & 0,53 & 0,50 & 0,33 & 0,32 & 0,31 & 0,42 & & & $-0,67$ & & \\
\hline $\mathbf{A K M}$ & & & & 0,29 & 0,44 & 0,47 & 0,44 & & & & & & \\
\hline TS & & & & & & & & & & $-0,29$ & $-0,41$ & & \\
\hline TA & & & & & & 0,26 & 0,27 & 0,30 & & $-0,32$ & & $-0,34$ & \\
\hline $\mathrm{NO}_{2}$ & & & & & & & 0,99 & & 0,28 & & & & \\
\hline $\mathbf{N H}_{4}$ & & & & & & & & & 0,28 & & & & 0,26 \\
\hline $\mathrm{NO}_{3}$ & & & & & & & & & & & $-0,49$ & $-0,26$ & \\
\hline TN & & & & & & & & & & & & & 0,26 \\
\hline
\end{tabular}

Tablo 3. Sedimentte toplam azot ve toplam fosforun ortalama ( \pm standart sapma) değerlerinin değişimi (mg $/ \mathrm{kg})$

\begin{tabular}{lllll}
\hline \hline & I & II & IV & V \\
\hline SD-TN & $841 \pm 58^{\mathrm{a}}$ & $1121 \pm 58^{\mathrm{b}}$ & $1354 \pm 66^{\mathrm{bc}}$ & $1436 \pm 58^{\mathrm{c}}$ \\
SD-TP & $101 \pm 21^{\mathrm{ab}}$ & $95 \pm 18^{\mathrm{a}}$ & $134 \pm 14^{\mathrm{bc}}$ & $145 \pm 11^{\mathrm{c}}$ \\
\hline \hline
\end{tabular}

Aynı satırda farklı üstel harflerle gösterilen değerler istatistiksel olarak önemli farklılığı temsil eder; P < 0,01; Tukey’s HSD

SD-TN değerleri incelendiğinde 1 nolu istasyonun 2,4 ve 5 nolu istasyondan farkl1, 2 nolu istasyon ise 5 nolu istasyondan farklı olduğu tespit edilmiştir $(p<0,05)$. SD-TP değerleri incelendiğinde ise 2 nolu istasyonun 4 ve 5 nolu istasyondan farkl1, 5 nolu istasyonun ise 1 nolu istasyondan farklı olduğu belirlenmiştir $(\mathrm{p}<0,05)$ (Tablo 3).

\section{TARTIŞMA ve SONUÇ}

Karapınar deresinde, Wetzel ve Likens (2000)'e göre belirlenen y1llık ortalama debi $20,18 \mathrm{~m}^{3} / \mathrm{s}$ olarak tespit edilmiştir.

Çalışmamız sonucunda sıcaklık değerleri en yüksek $17,9{ }^{\circ} \mathrm{C}$ ile Ekim ayında 5. istasyonda, en düşük ise $15,6{ }^{\circ} \mathrm{C}$ ile Ocak ayında 5. istasyonda belirlenmiştir. Su sıcaklığında gözlenen değişimin mevsimsel koşullara uygun olduğu tespit edilmiştir. İstasyonlar arasında su sıcaklık değerleri önemli bir farklılık göstermemiştir ( $>>0,05)$. Karapınar Deresi'nin su sıcaklığı, Taşdemir ve Göksu (2001), Özbay vd., (2011) ve Taş vd., (2010)'nin çalışmalarında belirttiği gibi mevsimsel olarak değişim göstermiş ve normal değerler içinde seyretmiştir.

pH değerleri, 7 - 7,94 aralı̆̆ında değişim gösterirken, en düşük Ocak ayında 1. istasyonda, en yüksek ise Aralık ayında 5. istasyonda ölçülmüştür. Pulatsü vd., (2004) tarafından çiftliklerin pH üzerine önemli etkisi olmadığı bildirilirken, çalışmamızda istasyonlardaki $\mathrm{pH}$ değişimi incelendiğinde 1. istasyonun diğer istasyonlardan farklı olduğu tespit edilmiştir $(p<0,05)$. 1. istasyonda gözlenen düşük $\mathrm{pH}$ değeri, istasyonun kaynak noktasına yakın olmasından dolayı kaynak sularının oksijence düşük olmasına bağlanmıştır. Yıldırım ve Pulatsü (2011), yaptıkları çalışmada büyük ve orta ölçekli işletmelerin giriş ve çıkış sularındaki pH değişiminin istatistiksel olarak önemli olduğunu bildirirken, çalışmamızda işletmelerin giriş ve çıkış sularında $\mathrm{pH}$ değeri bakımından önemli farklılığın olmaması, işletmelerin çok küçük kapasiteli olmasına bağlanmıştır.

Çalışmamızda çözünmüş oksijen değeri 6,04 - 9,75 mg/l aralığında değişirken, en düşük ölçüm Ocak ayında 1. istasyonda, en yüksek ölçüm ise Şubat ayında 5. istasyonda gözlenmiştir. İstasyonların ortalama çözünmüş oksijen değerleri 1 . istasyondan sonra artış göstermektedir. $\mathrm{Bu}$ durum, 1 . istasyonun kaynağa yakın ve kaynak sularının oksijence düşük olmasına bağlanmıştır. Pulatsü vd., (2004) ve Tekinay vd., (2009), yetiştiricilik tesislerinin çıkış sularının çözünmüş oksijen miktarının yetiştiricilik aktivitelerinden dolayı düştüğü bildirirken, çalışmamızda bu durumun tersine, derenin aşağısına doğru artış göstermiştir. $\mathrm{Bu}$ artışın, çalışma alanında yer alan tesislerin yetiştiricilik 
kapasitesinin düşük ve yemleme yoğunluğunun az olmasıyla birlikte, dere yatağı eğiminin fazla olması ve dere yatağının dar olmasından kaynaklandığı düşünülmüştür. Oksijen düzeyinin 1 . istasyondan 5. istasyona doğru artması ve mevsimsel olarak fazla değişim göstermemesi, istasyonlar arası mesafenin az olması ile ilişkilendirilmiştir.

Y1l boyunca izlenen elektriksel iletkenlik değeri, en yüksek 545,00 $\mu \mathrm{s} / \mathrm{cm}$ ile Aralık ayında 2. istasyonda, en düşük 431,00 $\mu \mathrm{s} / \mathrm{cm}$ ile Haziran ayında 1 . istasyonda belirlenmiş, mevsimsel olarak debinin düşük olduğu kışın en üst seviyede seyreden elektriksel iletkenlik değerleri, ilkbaharda, kar ve yağmur sularının dereye karışmasından dolayı azalmıştır. Su ürünleri standartları ve yüzey sularının kirlenmeye karşı korunmasını içeren protokolde elektriksel iletkenlik değerlerinin 150-500 $\mu \mathrm{S} / \mathrm{cm}$ aralığında olması gerektiği (Taş vd., 2010) belirtilmektedir. Bu çalışmada, ortalama elektriksel iletkenlik değerlerinin, Taş vd., (2010)'nin belirttiği aralığın üst limitinin hafif dışında kaldığı görülmektedir. Taş vd., (2010)'nin bildirdiğine göre elektriksel iletkenlik değerleri, yağış miktarı ve bölgenin jeolojik yapısına göre değişmektedir. Bölgenin dolomit ve kalker kayaçlarla kaplı olması sebebiyle elektriksel iletkenlikte yükselmeye neden olduğu düşünülmüştür (Anonim, 2008).

Askıda katı madde değerleri en yüksek $18,2 \mathrm{mg} / 1$ ile Ağustos ayında 3. istasyonda, en düşük 0,1 $\mathrm{mg} / \mathrm{l}$ ile Nisan ayında 4. istasyonda belirlenmiştir. Çalışmamızda gözlenen bu değişim, Pulatsü vd., (2004)'nin bildirdiği gibi, ilkbaharda debinin artması nedeniyle düştüğü ve yazın ise düşük debiyle birlikte alabalık tesislerinde hasat ve temizlik aktiviteleri ile çevredeki evsel, hayvansal ve tarımsal kaynaklardan arttı̆̆ 1 düşünülebilir.

Klorofil- $a$ değeri en düşük $0,12 \mu \mathrm{g} / 1$ ile Kasım ayında 3. istasyonda, Haziran ayında 4. istasyonda, Mart ayında 5. istasyonda, en yüksek 11,38 $\mu \mathrm{g} / 1$ ile Haziran ayında 5. istasyonda belirlenmiştir. İstasyon 5 'teki klorofil- $a$ düzeyinin yüksek olması bu istasyonun sığ, akıntı hızının düşük ve klorofil- $a$ düzeyinin sıcaklıkla birlikte artmasına bağlanmıştır. Akarsu sistemlerinde klorofill- $a$ değişimlerinin her zaman besin elementi yükünü yansıtmadığı belirtilmiştir (Cloern, 2001). Bu çalışmada, Özbay vd., (2012)'nin çalışma sonuçlarına benzer olarak, besin elementleri ile klorofil- $a$ arasında doğrusal bir ilişki belirlenememiştir. Bu durum çalışma sahasının akarsu sistemi olması ile ilişkilendirilmiştir (Odabaşı ve Büyükateş, 2009). Haziran ayında özellikle 5. istasyondaki ani artışın, akarsu debisinin bu mevsimde düşük olması ve sıcaklıkla ilişkili olduğu düşünülmüştür.

Toplam alkalinite değeri en düşük $280 \mathrm{mg} \mathrm{CaCO} / 1$ ile Şubat ayında 4. istasyonda, en yüksek 510 $\mathrm{mg} \mathrm{CaCO}_{3} / 1$ ile Ocak ayında 1. istasyonda gözlenmiştir. Mersin ili topraklarının \%45,8'i çok fazla kireçli olduğundan (Türkoğlu vd., 2007), bu yüksek değerlerin bulunduğu düşünülmüştür. Yapılan birçok araştırmada toplam alkalinite değerlerinin akım ile ilişkili olduğu ve akımın yüksek olduğu dönemlerde düşük, akımın düşük olduğu dönemlerde ise yüksek olduğu ifade edilmiştir (Şen vd., 2002; Varol, 2004; Ouyang vd., 2006). Bu durum, çalışmamızda tespit edilen toplam alkalinite değerleri ile ilgili bulguları desteklemektedir.

Toplam sertlik değeri ise en yüksek 397,1 $\mathrm{mg} \mathrm{CaCO}_{3} / \mathrm{l}$ ile Ocak ayında 2. istasyonda, en düşük 285 mg $\mathrm{CaCO}_{3} / \mathrm{l}$ ile Haziran ayında 2. istasyonda ölçülmüştür. Mevsimsel olarak toplam sertlik değeri, sonbahar mevsiminde diğer mevsimlere göre yüksek bulunmuştur. İstasyonlar arasında ise toplam sertlik değeri 1. istasyondan itibaren artış göstermiş ve 2. istasyonda en yüksek değere $(397,1 \mathrm{mg}$ $\left.\mathrm{CaCO}_{3} / \mathrm{l}\right)$ ulaşmıştır. Chapman ve Kimstach, (1996) ve Risch (2004), akımın düşük olduğu aylarda ortalama toplam sertlik derişiminin arttığını, akımın yüksek olduğu aylarda ise azaldığını ifade etmişlerdir. Çalışmamızda toplam sertlik, debinin yüksek olduğu ilkbaharda düşüş, diğer mevsimlerde artı̧̧ göstermiştir. Yüksek çıkan toplam sertlik değerlerinin nedeni olarak, bölgenin genelinin dolomit ve kalker kayaçlarla kaplı olması söylenebilir. (Anonim, 2008; Öner vd., 2005).

Kimyasal oksijen ihtiyacı değerleri (KOİ) en yüksek $79 \mathrm{mg} / \mathrm{l}$ ile Ağustos ayında 3. istasyonda, en düşük ise $27 \mathrm{mg} / \mathrm{l}$ ile Şubat ayında 2. istasyonda tespit edilmiştir. Illk işletmenin çıkışından (İstasyon 2) ikinci işletmenin girişine kadar (İstasyon 3) ortalama KOİ değeri $(55 \mathrm{mg} / \mathrm{l})$ artı̧̧ göstermiştir. Bu artışın, alabalık işletmelerinin yanı sıra evsel, hayvansal ve tarımsal alanlardan dereye karışan organik maddelerden kaynaklandığı düşünülmüştür. Tespit edilen KOİ değerleri Midlen ve Redding (1998) tarafından balık işletmeleri çıkış sularında havuzların temizlendiği dönem dışında belirtilen kimyasal oksijen ihtiyacı değerlerinden (8,0-24 mg/l) ve Pulatsü vd. (2004) tarafindan Karasu Deresi üzerinde ardarda kurulu beş gökkuşağı alabalığı işletmesi çıkış sularında maksimum 6,32 mg/l olarak belirtilen değerden daha yüksek bulunmuştur.

Çalışmamız sonucunda nitrit azotu değerleri, en yüksek $0,015 \mathrm{mg} / \mathrm{l}$ ile Aralık ayında istasyon 5'te, en düşük 0,001 mg/l ile Ocak ve Şubat aylarında istasyon 3'de, Nisan ayında istasyon 4'de, Haziran 
ayında istasyon 2'de ve Kasım ayında istasyon 5'de ölçülmüştür. Koçer ve Sevgili (2014), alabalık çiftliklerinin etkisinin olduğu istasyonlardaki ortalama nitrit azotu aralığını 0,007-0,022 mg/l olarak tespit etmişlerdir. Çalışma alanımızda yer alan işletmelerin düşük kapasiteye sahip olmasından dolayı nitrit azotu değerleri bu çalışmaya göre düşük düzeyde çıkmıştır. 1. istasyondaki yüksek nitrit azotu düzeyi, bu istasyonun kaynağa yakın olması nedeniyle nitrifikasyon olayının ara ürünü olmas1 şeklinde değerlendirilmiştir. Diğer istasyonlardaki artı̧̧ların ise evsel, tarımsal ve karasal hayvan yetiştiriciliğinden gelen kirleticilere ek olarak alabalık çiftliklerinde balık biyomasının değişimine bağlı yemleme oranlarından kaynaklandığı düşünülmektedir.

Karapınar Deresi'nde nitrat azotu en yüksek değer $0,87 \mathrm{mg} / \mathrm{l}$ ile Temmuz ayında 1 . istasyonda, en düşük ise $0,54 \mathrm{mg} / \mathrm{l}$ ile Ocak ayında 4 . istasyonda tespit edilmiştir. 1. istasyondan 2. istasyona nitrat azotu artışının nedeninin, çiftlik atık sularının yanı sıra 1. istasyondaki yüksek düzeydeki nitritin nitrifikasyon sonucu nitrata dönüşmesi olduğu düşünülmüştür. Çalışmada nitrat azotu mevsimsel olarak dalgalanmalar göstermiştir. Karapınar Deresinin balık işletmelerinin yanı sıra Tepe vd., (2006) ve Fianko vd., (2010)'nin belirtikleri gibi evsel, tarımsal ve büyükbaş hayvan yetiştiriciliğinden etkilendiği sonucuna varılmıştır.

Amonyum akarsu ve göllerdeki bitkiler, algler ve bakteriler için çok önemli azot kaynağı olup sularda çok düşük miktarlarda bulunmakta ve çok çabuk form değiştirmektedir (Wetzel ve Likens, 2000). Kirlenmemiş akarsular 0,005-0,04 mg/l aralığında amonyum azotu içermektedir (Wetzel, 2001). Karapınar Deresi'nde gözlenen ortalama amonyum azotu değerleri en yüksek $0,033 \mathrm{mg} / \mathrm{l}$ ile Mayıs ayında 1. istasyonda, en düşük ise $0,018 \mathrm{mg} / \mathrm{l}$ ile Kasım ayında 5. istasyonda tespit edilmiştir olup Wetzel (2001)'in amonyum azotu bakımından kirlenmemiş sular için belirtmiş olduğu değerler arasında kalmıştır. Helfrich (1998)'in alabalık çiftliklerinin akarsu üzerindeki kirlilik yükünü belirlemek amacıyla yaptığı bir çalışmada akarsuyun alt bölgelerine doğru su debisinin azaldığı kısımlarda, amonyum azotu miktarının artış gösterdiğini bildirmiştir. Bu çalışmada benzer olarak özellikle yaz aylarında su debisini azaldığı dönemlerde, amonyum azotu miktarının artış gösterdiği görülmüştür.

Karapınar Deresi'nde ortofosfatın en düşük değeri $0,002 \mathrm{mg} / 1$ ile Aralık ayında 4. istasyonda, en yüksek değeri ise $0,009 \mathrm{mg} / 1$ Mayıs ayında yine 4. istasyonda tespit edilmiştir. İstasyonlar incelendiğinde, ortofosfat düzeyleri tüm istasyonlarda benzer seviyede seyrederken, Mayıs ayında 4. istasyonda ani bir artış görülmüştür. Bu artışın sebebi olarak 4. istasyonda suyun tarım alanlarında kullanılan gübrelerin yağmur suları ve sulama kanalları ile taşınmasına ve balık çiftliklerinden artan yemleme ve balık biyomasına bağlı olarak gelen kirlilik yükünün bu mevsimde bu bölgede birikim göstermesine bağlanmıştır. Fytianos vd., (2002)'nin bildirdiğine göre, ötrofikasyon riskinin oluştuğu nehir sularında, fosfat alt limiti $0,5 \mathrm{mg} / \mathrm{l}$ olduğunu bildirmiş olup, çalışma bulgularımızda bu sınır değerin aşılmadığı görülmüştür. Reynolds (1993), alg gelişimi için ortofosfat konsantrasyonunun 0,01 $\mathrm{mg} / \mathrm{l}$ 'den düşük olmaması gerektiğini bildirmiştir. Çalışmamızda ortofosfat konsantrasyonları ortalama değerlerine bakıldığında tüm istasyonların $0,01 \mathrm{mg} / \mathrm{l}$ 'nin altında kaldığ 1 belirlenmiştir.

Çalışmada toplam azot (TN) değerleri en yüksek $1,07 \mathrm{mg} / 1$ ile Şubat ayında 1 . istasyonda ve en düşük ise $0,68 \mathrm{mg} / 1$ ile Ocak ayında 2. istasyonda tespit edilmiştir. Toplam azot değerlerinin Ocak ayında düşüş göstermesinin, artan su debisinden kaynaklandığını söyleyebiliriz. Pulatsü ve Çamdeviren (1999), alabalık yetiştiriciliği çıkış suyunun kalitesini değerlendirmek amacıyla yaptıkları bir çalışmada toplam azot değerini $0,49 \mathrm{mg} / \mathrm{l}$ olarak tespit etmişler ve bu değerin alabalık üretimi için kabul edilebilir standart değerler içerisinde olduğunu bildirmişlerdir. Bu çalışmaya benzer olarak, bulduğumuz toplam azot değerlerinin kabul edilebilir standart değerler içerisinde olduğu tespit edilmiştir.

Çalışmada süresince toplam fosfor (TP) değerleri en yüksek $0,030 \mathrm{mg} / 1$ ile Nisan ayında 1 . istasyonda, en düşük ise $0,016 \mathrm{mg} / 1$ ile Kasım ayında yine 1 . istasyonda tespit edilmiştir. Nisan ayındaki artışın sebebinin, bu ayda alabalık çiftliklerinde artan balık miktarıyla birlikte, yemleme ve dışkı miktarından kaynaklı olduğu söylenebilir. Toplam fosfor düzeyinin 1. istasyonda diğer istasyonlara göre fazla çıkması, bu bölgede tarımsal arazilerden, evsel ve çevresel atıklardan yeraltına suların sızdığını düşündürmüştür. Suda TN/TP oranları 1. istasyonda: 46; 2. istasyonda: 47; 3. istasyonda: 46; 4. istasyonda: 48 ve 5. istasyonda; 46 olarak belirlenmiştir.

Çalışma sonucunda sedimentte toplam azot (SD-TN) değerleri mevsimsel olarak en düşük 700,5 $\mathrm{mg} / \mathrm{kg}$ olarak 1. istasyonda kış mevsiminde, en yüksek ise $1542,1 \mathrm{mg} / \mathrm{kg}$ ile yaz mevsiminde akıntı hızının düştüğü, sığ ve balçık sediment yapısına sahip olan 5. istasyonda belirlenmiştir. Bu durum, 
Cüce ve Bakan (2005) tarafından belirtildiği gibi, bölgede karasal ve sucul bitkilerin yoğun olması ve cansız bitki, yem ve dışkı atıklarının ve yağmur suları ile taşınan azotun sedimentte çökerek birikmesi ile açıklanabilir. Sedimentte azot ve fosfor birikiminin aynı zamanda su akış hızı ve kirlilik süresiyle de ilişkili olduğu bildirilmiştir (Wetzel, 2001). SD-TN düzeyi mevsimsel olarak incelendiğinde su debisinin yüksek olduğu kış dönemde en az birikim gözlenirken, yazın su debisinin azalması sedimentteki azot düzeyinde artmasına neden olmuştur. Çalışmamızda 5. istasyona kadar sedimentteki azotun su akışı ile birlikte taşındığı ve bu istasyonda akış hızının düşerek suyun sığlaşmasından dolayı sedimentte birikim gösterdiği belirlenmiştir.

Sedimentte toplam fosfor (SD-TP) değeri ise mevsimsel olarak en yüksek $156,14 \mathrm{mg} / \mathrm{kg}$ ile 5 . istasyonda yaz mevsiminde, en düşük ise $76,52 \mathrm{mg} / \mathrm{kg}$ ile 2 . istasyonda $\mathrm{k} 1 s ̧$ mevsiminde tespit edilmiştir. İstasyonlardaki SD-TP düzeyi karşılaştırıldığında, 5. istasyonda toplam fosfor yükünün en fazla olduğu görülmüş, bunun sebebi olarak bu istasyonda su akıntı hızı düşerek derenin sığlaşmasına ve balçık sediment yapıya sahip olmasına bağlanmıştır. 2. istasyonda gözlenen en düşük SD-TP düzeyinin ise suyun akış hızının fazla ve Mainstonea ve Parr (2002)'ın belirttiği gibi sedimentin kumlu yapıya sahip olmasından dolayı fosforun sedimentte birikimi düşük olması ile açıklanmıştır. Toplam fosfor mevsimsel olarak yazın azalan su debisinden dolayı çevresel (evsel, hayvansal, tarımsal) kirleticiler ile balıklar tarafından yenemeden su ortamına karışan yemlerden ve balık dışkılarından gelen fosfor yükünün sedimentte birikmesi dolayısıyla artış göstermiş, kış mevsiminde ise artan su debisiyle birlikte tekrar azalmıştır. İstasyonlardaki ortalama SD-TP değerleri ise $95-145 \mathrm{mg} / \mathrm{kg}$ aralığında belirlenmiştir. İkinci işletmenin giriş noktası olan 3. istasyonda yüksek akıntı hızı ile birlikte sediment yapısının kayalık olmasından dolayı sediman birikimi olmadığı için örnekleme yapılamamıştır.

Su ürünleri yetiştiriciliğinin artmasıyla birlikte çevre sorunları da son yıllarda ön plana çıkmaya başlamıştır. Sebebi ise yetiştiricilik faaliyet alanlarının artmasıyla birlikte oluşan kirlilik yükünün hissedilir derecede olmasıdır. Bu çalışmada aradığımız sonuç, dere ve akarsularda yapılan yetiştiricilik çevreyi kirletiyor mu, yoksa suyun belirli hızdaki akışından dolayı su kendini devamlı yeniliyor mu sorusunun cevabını bulabilmektir.

Su kirliliği kontrol yönetmeliğine (SKKY, 2004) göre tüm istasyonların ortalaması bakımından Karapınar Deresi; sıcaklık, pH, çözünmüş oksijen, nitrat azotu, amonyum azotu ve toplam fosfor yönünden I. sınıf; nitrit azotu bakımından II. sınıf ve kimyasal oksijen ihtiyacı bakımından 2 . ve 5 . istasyonlar II. sınıf, 1., 3. ve 4. istasyonlar ise III. sınıf olarak belirlenmiştir. Doods vd., (1998) akarsu sistemlerini toplam azot düzeyine $(\mathrm{mg} / \mathrm{l})$ göre yaptıkları sinıflandırmada $<0,7$ oligotrofik, 0,7-1,5 mezotrofik ve $>1,5$ ötrofik olarak belirtmiştir. Buna göre Karapınar Deresi toplam azot düzeyi bakımından mezotrofik sinıfta yer almaktadır. Doods vd., (1998) akarsu sistemlerini toplam fosfor düzeyine $(\mathrm{mg} / \mathrm{l})$ göre yaptıkları sınıflandırmada $<0,025$ oligotrofik, 0,025-0,075 mezotrofik ve $>0,075$ ötrofik olarak belirtmiştir. Buna göre Karapınar Deresi toplam fosfor düzeyi bakımından oligotrofik sınıfta yer almaktadır. Doods vd., (1998), akarsu sistemlerini klorofil- $a$ düzeyine ( $\mu \mathrm{g} / \mathrm{l})$ göre yaptıkları sinıflandırmada ise klorofil- $a$ düzeyi $<10$ oligotrofik, 10-30 mezotrofik ve $>30$ ötrofik olarak belirtmiştir. Bu sınıflandırmaya göre Karapınar Deresi klorofil- $a$ düzeyi bakımından oligotrofik sınıfta yer almaktadır. Karapınar Deresi trofik sınıflandırmaya göre, klorofil- $a$ ve toplam fosfor düzeyi bakımından oligotrofik, toplam azot düzeyi bakımından mezotrofik sinıfta yer almaktadır. Sularda toplam azot (TN)/toplam fosfor (TP) oranı algal büyümeler için sınırlayıcı besin elementinin tespit edilmesi için yaygın olarak kullanılmaktadır. Eğer TN/TP $<10$ ise azot, TN/TP $>17$ ise fosfor sınırlayıcı besin elementidir (Smith, 1982). TN/TP oranı incelendiğinde tüm istasyonlarda fosfor sınırlayıcı element olarak tespit edilmiştir. pH, çözünmüş oksijen, askıda katı madde, toplam alkalinite, toplam sertlik, nitrit azotu ve nitrat azotu değerlerinin EPA (1986)'nın belirtmiş olduğu limit değerlerin üzerine çıkmadığ 1 tespit edilmiştir.

Belirlenen istasyonlarda 1 yıl süreli çalışmalarda elde edilen veriler değerlendirilmiş ve tatlı sularda yapılan balık yetiştiriciliğinin akıntı sebebiyle, çeşitli faaliyetler sonucu oluşan kirlilik etmenlerinin büyük oranda elimine ettiği görülmüştür. Tüketilmeyen yemler ve balıkların metabolik faaliyetlerinden kaynaklanan atıklar yüksek debi sayesinde birikim yapmamaktadır.

Akarsular üzerinde yapılan su ürünleri yetiştiriciliğinde büyük boyutta kirlenme görülmemesine rağmen olası kirlilik faktörlerinin minimum seviyeye indirilmesi, yetiştiricilik sektörünün ilerlemesine yardımcı olacaktır. Her üç işletmenin de pelet yem kullandığı göz önüne alındığında, yüksek enerjili, sindirilebilirliği yüksek ve fosfor içeriği düşürülmüş ekstrude yem kullanımı ile işletmelerden 
kaynaklanan azot-fosfor yükünün azaltılarak su kalitesinin artırılması önemli bir unsur olarak görülmektedir. Bu sebeple, akarsular üzerinde yapılan yetiştiriciliğin çevreye etkisini azaltmak için işletmelerden çıkan atık suların arıtmaya tabi tutulması, suda istenilen süre kalabilen ve balıklar tarafindan tamamen tüketilebilecek yem tipleri kullanılması ve stoklama yoğunluğu gibi faktörlere dikkat edilmelidir. Böylelikle su ürünleri işletmelerinden kaynaklanan etkilerin en aza ineceği bir gerçektir.

Teşekkür: Bu çalışma, Yüksek Lisans tezinden özetlenmiştir. Bu çalışmanın gerçekleşmesinde maddi imkan sağlayan Mersin Üniversitesi Bilimsel Araştırma Projeleri (BAP) birimine (Proje No: BAPFBE SÜ (HMK) 2011-7 YL) katkılarından dolayı teşekkür ederiz.

\section{KAYNAKLAR}

Akkaya, C., Efeoğlu. A., \& Yeşil. N. (2006). Avrupa Birliği su çerçeve direktifi ve Türkiye'de uygulanabilirliği. TMMOB Su Politikalarl Kongresi, Ankara, 195-204.

Anonim, (2008). 2007 yılı Mersin il çevre durum raporu. Mersin Valiliği İl Çevre ve Orman Müdürlügü̈, Mersin, $328 \mathrm{~s}$.

Anonim, (2019). Su ürünleri istatistikleri. (Erişim tarihi: 11/08/2019). https://www.tarimorman.gov.tr/sgb/Belgeler/SagMenuVeriler/BSGM.pdf

APHA, (1998). Standard methods for the examination of water and wastewater (20th ed.). American Public Health Association, Washington DC USA.

Chapman, D., \& Kimstach, V. (1996). Selection of water quality variables. in: water quality assessments - a guide to use of biota, sediments and water in environmental monitoring. (Chapman, D.) University Press, Cambridge, 651p.

Cloern, J. E., (2001) Our evolving conceptual model of the coastal eutrophication problem. Marine Ecology Progress Series, 210, 223-253.

Cüce, H., \& Bakan, G. (2005). Kızılırmak Nehri'nde 'sediman oksijen ihtiyacı (soi)' belirleme çalışmaları (Poster Sunum). VI. Ulusal Çevre Mühendisliği Kongresi, 24-26 Kasım 2005, İstanbul.

Dodds, W. K., Jones, J. R., \& Welch, E. B. (1998). Suggested classification of stream trophic state: distributions of temperate stream types by chlorophyll, total nitrogen and phosphorus. Water Research, 32(5), 14551462.

EPA, (1986). Quality criteria for water. Washington, 477p.

Fadaeifard, F., Raissy, M., Faghani, M., Majlesi, A., \& Nodeh Farahani, G. (2012). Evaluation of physicochemical parameters of waste water from rainbow trout fish farms and their impacts on water quality of Koohrang Stream - Iran. International Journal of Fish Aquaculture, 4(8), 170-177.

FAO, (2018). The state of world fishers and aquaculture. Meeting The Sustainable Development Goals, Food and Agriculture Organization, Rome, 210p.

Fianko, J. R., Lowor, S. T., Donkor, A., \& Yeboah, P. O. (2010). Nutrient chemistry of the Densu River in Ghana. The Environmentalist, 30, 145-152.

Fytianos, K., Siumka, A., Zachariadıs, G. A., \& Beltsios, S. (2002). Assessment of the quality characteristics of Pinios River, Greece. Water, Air, and Soil Pollution, 136, 317-329.

Helfrich, L. A. (1998). Impacts of trout culture effluent on water quality and biotic communities in Virginia headwater streams. The Progressive Fish-Culturist, 60(4), 247-262.

Koçer, M. A. T., \& Sevgili, H. (2014). Parameters selection for water quality index in the assessment of the environment impacts of land-based trout farms. Ecologial Indicators, 36, 672-681.

Mainstonea, C. P., \& Parr, W. (2002). Phosphorus in rivers - ecology and management. The Science of The Total Environment, 282(283), 25-47.

Manoochehri, H., Abedi, M., Hashemi, M., \& Boustani, F. (2010). An assessment of fish processing plant discharge effluent on the Tizab River. World Academy of Science, Engineering and Technology, 46, 146147.

Millen, A., \& Redding, T. A. (1998). Environmental management for aquaculture. Kluwer Academic Publishers, London, 21-56p.

Odabaşı, S., \& Büyükateş, Y. (2009). Klorofil- $a$, çevresel parametreler ve besin elementlerinin günlük değişimleri: Sarıçay Akarsuyu Örneği (Çanakkale, Türkiye). Ekoloji, 19(73), 76-85.

Ouyang, Y., Nkedi-Kızza, P., Wu, Q. T., Shinde, D., \& Huang, C.H. (2006). Assessment of seasonal variations in surface water quality. Water Research, 40(20), 3800-3810.

Öner, E., Hocaoğlu, B., \& Uncu, L. (2005). Tarsus Ovası'nın jeomorfolojik gelişimi ve Gözlükule Höyüğü. Türkiye Kuvaterner Sempozyumu, 2-5 Haziran, İstanbul, 82-89. 
Özbay Ö., Göksu M. Z. L., \& Alp M. T. (2011). Bir akarsu ortamında (Berdan Çayı, Tarsus-Mersin) en düşük ve en yüksek akım dönemlerinde bazı fizikokimyasal parametrelerin incelenmesi. Fırat Üniversitesi Fen Bilimleri Dergisi, 23(1), 31-39.

Özbay Ö., Göksu M. Z. L., \& Alp M. T. (2012). Akarsu ortamında su kalite parametrelerinin incelenmesi, Berdan Çayı örneği (Tarsus-Mersin). Ç.Ü. Fen ve Mühendislik Bilimleri Dergisi, 28(1), 109-117.

Pulatsü, S., Rad, F., Köksal, G., Aydın, F., Karasu Benli, A. C., \& Topçu, A. (2004). The 1mpact of rainbow trout farm effluents on water quality of Karasu Stream, Turkey. Turkish Journal of Fisheries and Aquatic Sciences, 4, 09-15.

Pulatsü, S., \& Çamdeviren, H. (1999). Sakaryabaşı Alabalık Çiftliği giriş ve çıkış suyunun kalite özellikleri. Ankara Üniversitesi Ziraat Fakültesi Tarım Bilimleri Dergisi, 5(2), 30-359.

Reynolds, C. S. (1993). The Ecology of freshwater phytoplankton (ecology, biodiversity and conservation). Cambridge University Press, Cambridge, 384p.

Risch, M. R. (2004). Chemical and biological quality of surface water at the U.S. army atterbury reserve forces training area near Edinburgh, Indiana, Semptember 2000 through July 2001. Geological Survery WaterResources Investigations Report, 87,03-4149.

Saremi, A., Saremi K., Saremi, A., Sadeghi, M., \& Sedghi H. (2013). The effect of aquaculture effluents on water quality parameters of Haraz River. Iranian Journal of Fisheries Sciences, 12(2), 445-453.

SKKY, (2004). Su kirliliği kontrolü yönetmeliği, 31 Aralık 2004 tarih ve 25687 sayılı Resmi Gazete, Ankara.

Smith, A. J. E. (1982). Epiphytes and epiliths. in bryophyte ecology, London, Chapman and Hall, 191-227.

Şen, B., Koçer, M. A. T., \& Alp, M. T. (2002). Hazar Gölü’ne boşalan akarsuların bazı fiziksel ve kimyasal özellikleri. Furat Üniversitesi Fen ve Mühendislik Bilimleri Dergisi, 14(1), 241-248.

Tanigawa, T., Yamashita, A., \& Koizumi, Y. (2007). Effect of effluents from a new fish farming site on the benthic environment. Bulletin of Fish Research Agents, 19, 69-77.

Taş, B., Candan, A. Y., Can, Ö., \& Topkara, S. (2010). Ulugöl (Ordu)'ün bazı fiziko-kimyasal özellikleri. Journal of Fisheries Sciences, 4(3), 254-263.

Taşdemir, M., \& Göksu, Z. L. (2001). Asi Nehri'nin (Hatay, Türkiye) bazı su kalite özellikleri. Ege Üniversitesi Su Ürünleri Dergisi, 18(1-2), 55-64.

Tekinay, A. A., Güroy, D., \& Çevik, N. (2009). The environmental effect of a land-based trout farm on Yuvarlakçay, Turkey. Ekoloji, 19(73), 65-70.

Tepe, Y., Ateş, A., Mutlu, E., \& Töre, Y. (2006). Hasan Çayı (Erzin-Hatay) su kalitesi özellikleri ve aylık değişimleri. Ege Üniversitesi Su Ürünleri Dergisi, 23(1/1), 149-154.

Türkoğlu, E., Doğan, A., Serin, D. S., \& Özsoy, T. (2007). Kilikya akarsularının iyonik bileşimi ve su kalitesi üzerine bir çalışma. Türk Sucul Yaşam Dergisi, 3-5(5-8), 618-627.

Varol, M. (2004). Hazar Gölü'ne dökülen Behrimaz Çayı'nın fiziksel ve kimyasal özellikleri. Furat Üniversitesi Fen Bilimleri Enstitüsü, Yüksek Lisans Tezi, Elazı̆̆ 109 s.

Wetzel, R. G. (2001). Limnology; lake and river ecosystems. Academic Press, New York, California, 1006p.

Wetzel, R.G., \& Likens, G.E. (2000). Limnological analyses. Springer Science Business Media. United States of America, 435p.

Yıldırım, H. B., \& Pulatsü, S. (2011). Karada kurulu alabalık işletmeleri (Fethiye, Muğla) çıkış suları özelliklerinin yasal düzenlemeler çerçevesinde değerlendirilmesi. Ekoloji, 20, 48-54. 